\title{
O Cumbaru( Dipteryx alata Vog.), o desenvolvimento local e a sustentabilidade biológica no assentamento Andalucia, Nioaque/MS
}

Tonkabean (Dipteryx alata Vog.), Local Development and the Biological Sustainability in the Andalucia Settling, Nioaque/MS

\author{
Le Cumbaru (Dipteryx alata Vog.), le développement local et la soutenabilité \\ biolgique au Place Andalucia, Nioaque/MS \\ El Cumbaru (Dipteryx alata Vog.) el desarrollo local y la sostenibilidad biológica em el Sítio \\ Andalucia, Nioaque/MS
}

\author{
Rosemarly Fernandes Mendes Candil ${ }^{*}$ \\ Eduardo José de Arruda* \\ Andréa Haruko Arakaki**
}

Recebido em 8/8/2006; revisado e aprovado em 10/11/2006; aceito em 30/1/2007.

\begin{abstract}
Resumo: Este artigo contextualiza a importância da sustentabilidade biológica do Cumbaru (Dipteryx alata Vog.) e o aproveitamento das potencialidades da comunidade para o desenvolvimento local do assentamento Andalucia. O desenvolvimento em bases locais é hoje uma das alternativas mais fecundas, como caminho para a resolução dos graves problemas com os quais se defrontam os trabalhadores rurais e os municípios de predominância rural.

Palavras-chave: Assentamento; desenvolvimento local; sustentabilidade.

Abstract: This article contextualizes the importance of the biological sustainability of Tonkabean (Cumbaru) (Dipteryx alata Vog.) as well the utilization of the community's potential for the local development of the Andalucia settling. Development local-based is today one of the best alternative as a way of solving serious problems, which rural workers and municipalities face.

Key words: Settling; local development; sustainability.

Résumé: Ce article contxtualise l'importance de la soutenabilité biologique du Cumbaru (Dipteryx alata Vog) et l'utilité des potencialités de la communité por le développement local du place Andalucia. Le développement em bases locaux est aujourd'hui une des alternatives plus productifs comment le chemin por la résoution des graves problémers que les travailleurs ruraux s'affrontent et les villes de prédominance rural.

Mots-clé: Place; développement local; soutenabilité.

Resumen: Este artículo contextaliza la importáncia de la sotenibilidad biológica del Cumbaru (Dipteryx alata Vog) y el aprovechamiento de las potencialidades de la cominidad para el desarrollo local del sítio Andalucia. El desarrollo em bases locales es hoy uma de las alternativas más adecuadas cómo camino para la solución de los graves problemas com los trabajadores rurales y las localidades de predomináncia rural.

Palabras clave: Sítio; desarrollo local; sostenibildad.
\end{abstract}

\section{O Cumbaru e o desenvolvimento local}

O Cumbaru é um fruto do Cerrado, no entanto o Cerrado é um bioma de importância fundamental para a conservação da biodiversidade mundial, e cobre aproximadamente $22 \%$ do território nacional - área enorme de quase dois milhões de $\mathrm{km}^{2}$, ainda é uma das 25 áreas mundiais consideradas críticas para a conservação da diversidade, devido à enorme riqueza biológica e alta pressão antrópica a que vem sendo submetido por décadas (SILVA et al., 2001).

Afirma esta assertiva Novaes (2004, p. 2), quando cita:
Essa ocupação descuidada, devastadora do Cerrado está tendo e terá conseqüências muito graves, até mesmo e principalmente para a própria agropecuária. O Cerrado do centrooeste é o berço das águas brasileiras [...]. Todas as bacias hidrográficas estão em processo acelerado de degradação, por causa da forte erosão nas culturas de grãos, da poluição por agrotóxicos e de efluentes de criações [...]. Mais espantoso ainda é lembrar os estudos da Embrapa, segundo os quais se poderiam dobrar, até triplicar, a produtividade nas lavouras do Cerrado, com o uso de tecnologias mais modernas.

Essa formação vegetal tem sido explorada ao longo do tempo produzindo efeitos predatórios sem preocupação com sistemas

\footnotetext{
* Universidade Católica Dom Bosco-UCDB. (rosecandil@terra.com.br).

** Universidade Federal do Paraná-UFPR.
} 
de utilização racional que permitam a produção sustentada, em virtude das monoculturas de soja, milho, arroz e feijão, pastagens e utilização de pesticidas e agrotóxicos. A produção mecanizada não considera o valor da diversidade, apenas está fundamentada na exploração contínua e nos lucros auferidos.

Todavia, o desconhecimento do potencial de uso dos recursos naturais, o desrespeito às leis de proteção ambiental, as queimadas e a intensidade de exploração agrícola têm provocado prejuízos incalculáveis ao solo, à fauna, à flora e aos recursos hídricos, comprometendo a sustentabilidade desse ecossistema e colocando muitas espécies animais e vegetais em risco de extinção, principalmente no tocante às espécies fruteiras nativas (SILVA et al., 2001).

Partindo do princípio de que o Cumbaru é uma fruta do Cerrado e comercialmente viável para as comunidades regionais, e os recursos naturais disponibilizados servem de estímulo para o desenvolvimento local e para a sustentabilidade da diversidade, reforça este contexto Ávila et al. (2001), afirmando que o desenvolvimento local é um processo dinamizador da comunidade a fim de que a mesma reative a respectiva economia e todo o seu progresso de qualidade de vida sócio-cultural e meio ambiental.

O objetivo é formular e executar ações que, levando em conta as vocações locais, permitam a construção de processos de desenvolvimento cujos resultados beneficiem a maioria da população.

Moradores do assentamento Andalucia, hoje mais conscientes, trabalham ajudando a conservar e a recuperar áreas degradadas da região, fazendo inclusive extrativismo vegetal sustentável, onde os recursos destes auxiliam as famílias a melhorar sua condição de vida.

A combinação da ética, democracia e desenvolvimento são essenciais quando se pensa em políticas públicas e práticas sociais centradas na pessoa e em melhor qualidade de vida para a sociedade (MÁRTIN, 2001).

\section{Desenvolvimento local e sustentabilidade humana e biológica}

O desenvolvimento local se apóia na idéia e nos pressupostos de que a localidade dispõe de recursos econômicos, humanos, institucionais, ambientais e culturais; além de economias de escala não exploradas, que constituem seu potencial de desenvolvimento. A existência de um sistema produtivo capaz de gerar rendimentos crescentes, mediante a utilização dos recursos disponíveis e a introdução de inovações, garante a criação de riquezas e a melhora do bem estar da população.

No caso do Andalucia foi desenvolvido através dos anseios da comunidade o curso de tecelagem que se tornou uma importante meta do projeto da ECOA (ONG Ecologia e Ação), com produção de peças utilizando os recursos do Cerrado, além de a exploração de alguns frutos como o jatobá fazendo farinhas, biscoitos e bolos, o pequi fazendo licor e o Cumbaru com a torra de suas sementes, gerando renda, com uma produção sustentável.

Mendez (2001), destaca que a inovação é um instrumento que pode melhorar o funcionamento das atividades econômicas, elevar sua capacidade competitiva e dos territórios que fazem parte, melhorar a qualidade do emprego e sustentabilidade ambiental.

É oportuno observar que em iniciativas desta natureza, é essencial buscar a maior articulação institucional possível para a execução dos projetos e ações pública e priva$\mathrm{da}$, nesses espaços, com atores locais e seus recursos disponibilizados, pois desde o final da década de 1980, a direção do MST, percebeu que a luta pela terra se desdobra necessariamente pela luta pela viabilização econômica dos assentados. Acredita-se que as dificuldades dos assentados provêm de sua pouca capitalização que cerca sua atividade na terra: não há suficiente acesso às tecnologias, aos insumos e às máquinas que permitem aumentar a produtividade.

A esse respeito Silveira (2001, p. 33), em seu artigo sobre ações integradas e desenvolvimento local: oportunidades e caminhos, afirma que:

A avaliação de iniciativas sob o desenvolvimento local deve ter como referência a relação 
entre o espaço local e novos arranjos sócios produtivos e inovações institucionais que unifiquem estrategicamente e potencializem as ações para o desenvolvimento, com acento na dimensão endógena.

Este contexto tem a ver com o efetivo interesse, disposição e disponibilidade das pessoas pelo enfrentamento dos problemas numa perspectiva coletiva e não individualista, depende das potencialidades locais, é um processo de desabrochamento que faz com que a comunidade encontre seus objetivos, é um desenvolvimento centrado.

O desenvolvimento local pode ser visto como um foco de intervenção no contexto da crise do desenvolvimento em condições de desigualdade e pobreza, visando a reconstrução das políticas e das ações a partir das potencialidades endógenas e das brechas do local, além de se caracterizar no território, em torno de três dimensões interligadas: a formação do capital humano, o desenvolvimento produtivo do território e a concentração participativa para gestão do desenvolvimento (SILVEIRA et alii., 2001, p. 26).

Na busca de um novo modelo de desenvolvimento descentralizado e democrático, que tenha o ser humano como centro e que privilegie a realização da reforma própria com a implantação e fortalecimento da agricultura familiar, os processos de participação nas decisões, responsabilidades e ações, são essenciais para garantir a perenidade dos projetos e a construção cotidiana da cidadania.

A cooperação é uma forma de relação social, onde quanto mais as pessoas se envolvem em relação de cooperação, mais se desenvolvem moral e intelectualmente, estabelecendo mais relações cooperativas entre si, melhorando ainda mais as relações.

Putnan (1996) informa que as regras sociais transferem para cada participante $\mathrm{o}$ direito de controlar as ações porque elas têm externalidades (conseqüências positivas ou negativas) sobre cada um deles. As regras seriam incutidas por meio de condicionamento e socialização, como também de sanções; já a reciprocidade seria uma das regras sociais mais importantes da cooperação: eu te ajudo na expectativa de que me ajudarás futuramente.

Durston (1999, p. 116),

Sugere medidas para desenvolver o capital social comunitário rural, dentre elas ressaltase: a) realizar uma busca de normas e práticas sobre confiança, reciprocidade e cooperação em grupos locais de ascendência em culturas rurais aparentemente dominadas pelo individualismo e familiarismo; b) analisar e aproveitar condições favoráveis para o ressurgimento do capital social, criada pela debilidade do clientelismo autoritário; c) oferecer oportunidades de criação de laços familiares e cooperação em nível comunitário; d) desenvolver uma rápida capacidade de resposta nos projetos e programas, para combater as ações dos atores clientelistas nos processos de transição; e) fomentar o desenvolvimento da capacidade de negociação estratégica dos dirigentes camponeses; f) outorgar prioridade ao fomento do sentido de missão entre os funcionários de um projeto, orientado ao desenvolvimento de capital social autônomo; g) tomar medidas para assegurar que o capital social cívico das comunidades ofereça benefícios materiais em curto prazo e, contribua para a habilitação no terreno político.

O Movimento dos Sem Terra (MST), desenvolveu formas de cooperação que permitem aos agricultores assentados superar em conjunto as dificuldades próprias que recaem sobre os produtores quando atuam isoladamente, desta forma encontram formas de adquirir equipamentos, tecnologia e preços de produtos mais favoráveis. Portanto, a cooperação entre os assentados traz mais vantagens que o isolamento.

O capital social é um recurso que abre caminhos para estabelecer novas relações entre os habitantes de uma comunidade. A esse respeito Jara (1999, p. 4), em seu artigo sobre a construção de redes de confiança e solidariedade afirma que:

A transição para uma sociedade sustentável será um processo possível quando sejam valorizados certos elementos estratégicos invisíveis, como o capital humano e o capital social, a participação social e o empoderamento das pessoas e organizações. [...] A insustentabilidade é conseqüência de nossos próprios atos, ou seja, nossa visão de mundo. Precisamos de novas fontes de poder, uma consciência radical fundamentada em sentimentos de confiança e necessidades compartilhadas.

O Movimento dos Sem Terra (MST) desenvolveu metodologias destinadas a alterar a mentalidade e diminuir a resistência dos assentados às práticas da economia solidária, voltou-se a pesquisa no campo da educação, vinculando-a ao desenvolvimento das condições intelectuais, individuais necessárias à sobrevivência econômica dos assentados. Desta forma aumenta-se o empoderamento dos assentados e desenvolve-se a confiança e solidariedade do grupo e aumenta a credibilidade do movimento. 
Kliksberg (1999) relata que o desenvolvimento cultural das sociedades é um fim em si mesmo, e avançar neste campo significa enriquecer espiritual e historicamente uma sociedade e seus indivíduos. A cultura dos pobres é estigmatizada, gerando a baixa auto-estima, enfraquecendo sua identidade e conclui que uma auto-estima fortalecida pode ser um potente motor de construção e criatividade individual, com repercussão grupal.

A transição para uma sociedade sustentável é um problema de consciência do grupo que começa na mudança interna das pessoas, nos sentimentos de solidariedade, no compromisso do ser humano com os demais e com a natureza.

O desenvolvimento e a integração, de novas informações, a formulação de novos conceitos e o aumento das colaborações interdisciplinares é essencial para o desenvolvimento e a adoção das técnicas emergentes para a sustentabilidade do agroecossistema (BORGES, 2003).

A exploração predatória do Cerrado faz com que a população brasileira sofra direta e indiretamente com a perda de qualidade de vida. A perspectiva de unir equilíbrio ambiental a benefícios econômicos aponta uma tendência que pode garantir o sustento das comunidades rurais ou urbanas.

As oportunidades locais de desenvolvimento dependem de cada localidade específica, pois depende de variáveis sociais e naturais internas e de variáveis de outras localidades e da globalidade, por efeito de escalas mais amplas como Municipal, Estadual e Nacional. O desenvolvimento local contribui com novas formas de produzir, dividir riquezas, materializar a cidadania, a democracia e a sustentabilidade da comunidade para que ela tenha "de que viver" e "razões para viver".

Costa (apud Marques e Martin, 2002, p.157), informam que:

Em Mato Grosso do Sul, nas áreas de Cerrado, a agricultura mecanizada e a criação extensiva de gado contribuíram significativamente para o aumento da produtividade média das culturas anuais e da pecuária de corte em anos recentes, porém, observam-se evidências ambientais que indicam que a presente forma de desenvolvimento agrícola é insustentável, favorecendo a degradação ambiental acelerada.

\section{O Capital social como fator estimulante para o desenvolvimento local da comunidade do assentamento Andalucia}

\begin{abstract}
Para Durston (1999, p.104),
O capital social é um conjunto de normas institucionais e organizacionais que promovem a confiança e a cooperação entre as pessoas, nas comunidades e na sociedade em seu conjunto, e sendo ele comunitário, englobando o conteúdo informal das instituições que tem por finalidade contribuir para o bem comum, sabe-se que em todos os grupos pequenos, em todas as partes, há normas e práticas de reciprocidade. A confiança, a cooperação, a identidade e a reciprocidade criadas na comunidade podem reproduzir-se entre os dirigentes, a fim de transformar o capital social de pequenas comunidades em um plano microrregional.
\end{abstract}

Para haver em uma comunidade o Desenvolvimento Local, é importante a confiança a cooperação a solidariedade entre as pessoas, o despertar de suas capacidades e a valorização das potencialidades locais bem como a responsabilidade da comunidade na sustentabilidade biológica local.

Conforme estudo feito por Candil (2004), no assentamento Andalucia, a grande maioria $(83 \%)$ dos assentados afirmam que existe confiança entre os assentados, sendo este um dado relevante para o trabalho de cooperação, pois segundo Jara (1999), a confiança fala da consciência de se sentir seguro, acreditar no outro, esperar com certeza e firmeza uma determinada resposta, depositar um senso de credibilidade e sintonia com a palavra do outro, o reconhecimento da lealdade do outro.

Ainda sobre este aspecto, Mendez (2001), afirma que a confiança mútua é requisito importante na existência de uma cultura de cooperação, baseada em certa prática compartilhadas e muitas vezes distintas a cultura estritamente econômica (fins culturais, políticos, sindicais, religiosos..), junto a presença de algum tipo de associação, são condicionantes que favorecem o estabelecimeto de relações onde a confiança é importante frente ao individualismo imperante nas relações de mercado.

Candil (2004) informa ainda que $65,22 \%$ da comunidade do Andalucia fazem parte de associações e 34,78\% não fazem parte. Entende-se por associação o ato ou efeito de associar-se, combinação, união, sociedade, agrupamento de seres que vivem 
em estado gregário, grupo de indivíduos que vivem por vontade própria sob normas comuns, comunidade (FERREIRA, 2001).

Para Kliksberg (1999), a existência de associações em uma sociedade indica que esta tem capacidades para atuar em forma de cooperativa, armando redes, com sinergias de toda ordem. Cita que o capital social contribui de forma importante a estimular a solidariedade e a superar as falhas do mercado através de ações coletivas e de uso comunitário de recursos.

Conforme o Plano de Consolidação do assentamento Andalucia (INCRA, 2002), o assentamento possui seis associações formais e duas informais, todas foram criadas sem fins lucrativos, com objetivos a prestação de quaisquer serviços que possam contribuir para o fomento e racionalização das atividades agropecuárias e a defesa das atividades econômicas, sociais e culturais de seus associados.

Afirmam $83 \%$ dos assentados do assentamento Andalucia que existe cooperação entre o grupo (CANDIL, 2004). A este respeito Jara (1999), informa que cooperação diz respeito a um processo de união entre as pessoas para conseguir um benefício comum, trabalhar junto com outros para construir um mesmo objetivo, afirma ainda que os relacionamentos de confiança, cooperação e reciprocidade facilitam a construção de processos de mudança social e desenvolvimento humano gerando sustentabilidade, enriquecendo o tecido social.

Desenvolver formas de cooperação nos assentamentos permite aos agricultores superar em conjunto as dificuldades que recaem sobre os produtores quando atuam isoladamente (POKER, 2003).

Diagnou-se também nesta comunidade segundo Candil (2004), que a grande maioria, 88\% dos assentados aceitam novas idéias, sendo que somente $9 \%$ não aceitam. A importância dos assentados aceitarem sugestões, e participarem de programas desenvolvidos para a e com a comunidade faz, com que o desenvolvimento endógeno seja estimulado, com conseqüente fortalecimento do conhecimento, da confiança mútua e da solidariedade. Estes são o sustentáculo e pressupostos básicos para a ocorrência do desenvolvimento local e da sustentabilidade.
Mendez (2001) relata que a inovação é um instrumento que pode melhorar o funcionamento das atividades econômicas locais, elevarem sua capacidade competitiva nos territórios que fazem parte, melhorar a qualidade do emprego e sustentabilidade ambiental.

É oportuno observar que em iniciativas desta natureza, é essencial buscar uma maior articulação institucional que torne possível para a execução de projetos com diferentes níveis de amplitude, por meio da implementação de ações públicas e privadas nos espaços com seus recursos disponibilizados junto aos atores locais.

\section{Considerações Finais}

O desenvolvimento sustentável pode surgir da organização solidária da comunidade Andalucia em torno de uma estratégia adequada e sustentável para preservar a vida humana e a biodiversidade. A partir dos dados coletados em nosso estudo pode-se concluir, apesar de certa organização local (associações), que a comunidade ainda está vulnerável em relação a esta questão. Podese observar que a organização precisa ser fortalecida, infra-estruturas (fomentar insumos agrícolas, maquinários, financiamentos) estabelecidas e estratégias implementadas para que a sensibilização dos assentados rurais reflita em trabalhos desenvolvidos com vistas ao fortalecimento das relações interpessoais e interinstitucionais, dos negócios e da orientação da produção local.

Nota-se que é importante o desenvolvimento de produtos alimentícios de frutos do Cerrado como o Cumbaru, que pode contribuir para a sustentabilidade de comunidades locais e também para a recomposição da paisagem natural e ao turismo, agregando valores ao turismo local, valorizando a caracterização de produtos típicos, como ocorre em outras regiões com suas comidas típicas e de custos acessíveis às camadas de menor faixa de renda da população é um grande estímulo ao estudo das leguminosas, e para a exploração racional deste produto por comunidades dos Cerrados, podendo ser uma opção de sustentabilidade da natureza e das comunidades que interagem com ela.

No entanto, sabe-se que o desconhecimento do uso adequado dos recursos 
naturais e a exploração predatória dos barueiros, com desrespeito as leis ambientais provocam prejuízos incalculáveis comprometendo a sustentabilidade deste ecossistema já fragmentado, pois a frequiência da exploração de sua madeira é normalmente em virtude do rápido retorno financeiro e da grande demanda. Mas os resultados obtidos pelos nossos estudos retratam que a comunidade está se preocupando mais com o futuro e com a sustentabilidade do bioma.

Portanto, em função das dinâmicas do assentamento e da constante busca de alternativas de sustentabilidade por parte da comunidade, alguns indicadores podem ser percebidos de que a localidade poderá alcançar níveis mais consistentes de renda e qualidade de vida, a partir do enfrentamento e resolução de seus problemas, mais urgentes, num viés de desenvolvimento com renda e qualidade de vida, praticado de modo solidário e igualitário e em harmonia com o meio ambiente, visando explorar o Cumbaru de forma racional e orientada.

\section{Referências}

ÁVILA, V. et al. (Org.) Formação educacional em desenvolvimento local: relato de um estudo em grupo e análise de conceitos. 2.ed. Campo Grande: UCDB, 2001.

BORGES, Miguel. A segurança alimentar e a sustentabilidade do agroecossistema. Disponível em: <http://www.mborges@asrr.arsusda.gov.htm>. Acesso em: 13 jan. 2003.

CANDIL, R.F.M. A capacitação construtiva local e o estímulo ao uso do cumbaru (Dipterix alata Vog.) no incremento de renda em assentamento rural: o caso do assentamento Andalucia, Nioaque/MS. Campo Grande: UCDB, 2004. Mestrado.

COSTA, R.B.; ARRUDA, E.J.; OLIVEIRA, L.C.S. Sistemas Agrossilvipastoris como alternativa sustentável para agricultura familiar. Interações - Revista_Internacional de Desenvolvimento Local. Campo Grande: UCDB, v.3, n.5, p.26, Setembro, 2002.

DURSTON, J. Construindo capital social comunitário. Revista da CEPAL, n.69, dez, 1999.

FERREIRA, A.B. de H. F. Mini Dicionário Aurélio Século XXI. O mini dicionário da língua portuguesa. 4.ed. Rio de Janeiro: Fronteira, 2001.

INCRA. Instituto Nacional de Colonização e Reforma Agrária. Programa de consolidação emancipação (autosuficiência) de assentamentos da reforma agrária. Plano de consolidação do assentamento Andalucia. Nioaque/MS, v.2, set., 2002.

JARA, Carlos Júlio. J. Capital social: Construindo redes de confiança e solidariedade. Capital social e desenvolvimento social sustentável. IICA, Quito: SEPLAN, nov., 1999.

KLIKSBERG.B. Capital social y cultura, claves essenciales del desarrollo. Revista da CEPAL, n.69, dezembro, 1999.

MARTIN, J.C. Desarrollo local para um nuevo desarrollo rural. Interações - Revista Internacional de Desenvolvimento Local. Campo Grande: UCDB, n.3, v.2, set., 2001.

MENDEZ, R. Innovación y resed de coopéración para el Desenvolvimento Local. Interações - Revista Internacional de Desenvolvimento Local. Campo Grande: UCDB, n.3, v.2, set., 2001.

NOVAES, W. Uma política para o Cerrado. Disponível em: <http:/ / www.cepen.com.br>. Acesso em: 4 abr. 2004.

PROKER, J. G. Cooperação e Cooperativismo no movimento dos trabalhadores rurais sem terra. Reforma agrária. Disponível em: <http://www.comciencia.br>. Acesso em: 5 abr. 2003.

PUTNAM, R. Capital social e desempenho institucional. In: Cap. VI da obra Comunidade e democracia: a experiência da Itália Moderna. FGV, 1996. RAMOS, J. B. Ecologia e Desenvolvimento, n.102, 2002.

SILVA, D. B. et al. Frutas do cerrado. Brasília: Embrapa Informação Tecnológica, 2001.

SILVEIRA, C.; BOCAYUVA, C.; ZAPATA, T. Ações integradas e desenvolvimento local: tendências, oportunidades e caminhos. São Paulo: EAESP/FGV. 